\title{
Passive Optical Combustion Sensors for Scramjet Engine Control
}

\author{
Daniel J. Micka ${ }^{1}$ and Darin A. Knaus ${ }^{1}$ \\ Creare LLC, Hanover, New Hampshire, 03755 \\ Jacob E. Temme ${ }^{2}$ and James F. Driscoll ${ }^{3}$ \\ University of Michigan, Ann Arbor, Michigan, 48109
}

\begin{abstract}
Dual-mode scramjet engines must operate over a wide range of flight conditions. Closed-loop engine control is necessary to maintain thrust and flame stability while preventing unstart over the flight envelope. High-frequency sensors and actuators are needed due to the short time scales associated with these engines. In the current research program we investigated the potential of passive optical combustion sensors for scramjet engine control. The sensors measure emissions of the $\mathrm{CH}^{*}$ and $\mathrm{C}_{2} *$ combustion radicals. The sensors were tested in a laboratory dual-mode scramjet combustor operated over a range of transients. We found that the sensors could be used to monitor equivalence ratio in key flame stabilization regions, predict flame flashback, track combustion oscillations, and analyze fuel placement. The sensor time response was very fast and the signal to background light level was strong. The results show passive optical sensors have great potential for use in high frequency scramjet engine controllers.
\end{abstract}

\section{Nomenclature}

$\begin{array}{ll}q & =\text { heat release rate } \\ \Phi & =\text { equivalence ratio } \\ \text { FADEC } & =\text { Full Authority Digital Engine Controllers } \\ \text { FFT } & =\text { Fast Fourier Transform } \\ \text { PMT } & =\text { Photo-Multiplier Tube } \\ \text { SNR } & =\text { Signal-to-Noise Ratio } \\ \text { TDLAS } & =\text { Tunable Diode Laser Absorption Spectroscopy }\end{array}$

\section{Introduction}

Dual-mode scramjet engines must operate over a wide range of flight Mach numbers (Mach 3.5 to $8+$ ). For relatively low-speed operation, such engines operate in the thermally choked ramjet mode. A pre-combustion shock train in the isolator slows the flow to a subsonic Mach number before the start of the combustor. Unstart occurs when the pre-combustion shock train moves outside of the isolator into the inlet. This causes an abrupt mass flow change to the engine which can be catastrophic to the vehicle. Optimal engine performance (combustion efficiency and thrust) is generally achieved when the engine is operating as close to isolator unstart as possible for low flight Mach numbers. Unstart can be caused by fluctuations in the heat release rate or position, shock-wave/boundary layer interactions, or incoming flow conditions.

Maintaining combustion stability over the scramjet flight envelope is also a challenge. At low flight Mach number, the combustion occurs as a flame which must be stabilized in a region of appropriate velocity, strain rate, and equivalence ratio. As the vehicle accelerates, the engine undergoes a transition from thermally choked, ramjet mode operation to fully supersonic, scramjet mode operation. There is an abrupt change in the isolator exit conditions and the penetration of wall fuel jets at this transition. This can lead to flame stability issues due to

\footnotetext{
${ }^{1}$ Engineer, 16 Great Hollow Road, Hanover, NH, AIAA Member.

${ }^{2}$ Post-Doctoral Research Fellow, Department of Aerospace Engineering, AIAA Member.

${ }^{3}$ Professor, Department of Aerospace Engineering, AIAA Fellow.
} 
changes in the stabilization region velocity and equivalence ratio. Additionally, most proposed scramjet concepts employ fuel cooling. As the vehicle heats up, the injected fuel transitions from a liquid to a vapor. This fuel vaporization greatly affects the fuel penetration and mixing and must be accounted for to maintain thrust and combustion stability through this transition.

Closed-loop control is necessary to maintain optimal scramjet engine performance (flame stability, thrust, unstart margin) over the flight envelope. In gas turbine engines, this closed-loop control is handled by a Full Authority Digital Engine Controller (FADEC) which takes in data from various sensors and adjusts fuel flow, vane angles, etc., to maintain optimal engine performance. An equivalent control system is needed which meets the unique requirements of scramjet engines. High-frequency sensors and actuators will be a key component of such control systems. Fluid and chemical time scales in these engines are very short. Sensors and actuators with $\mathrm{kHz}$ response rates are needed to sense and respond to transients such as ignition, flame instability, and unstart. These sensors and actuators must also be rugged to survive the harsh environment of the engine, lightweight, simple, and as minimally intrusive as possible.

Many types of sensors have been applied to scramjet engines in laboratory environments. Several studies have investigated the use of high-frequency isolator pressure sensors to detect and predict the onset of unstart. Most of these studies have investigated cold flow where the combustion blockage is simulated by a physical blockage. ${ }^{1-3}$ These studies have shown the usefulness and limitations of isolator pressure measurements for prediction of unstart and unstart margin. While pressure measurements can be used to obtain a prediction of imminent unstart, the advance warning time may be too short for effective actuation to arrest the event. ${ }^{1,2}$

Cold flow studies of isolator pressure measurements have allowed investigation of the unsteady fluid effects which can cause unstart but do not account for unsteadiness of the combustion. Combustion fluctuations will cause a change in the pre-combustion shock train and can be a major cause of unstart as noted by Ref 1. Ref. 4 and Ref. 5 found that changes in the reaction zone in a dual-mode scramjet precede major changes in the pre-combustion shock train. Therefore, measurements of the combustor may give more advance warning of unstart than isolator pressure measurements. Additionally, while isolator measurements are good indications of unstart margin, they do not give sufficient information to determine how to adjust fueling to maintain both the desired unstart margin and thrust. Combustor pressure measurements would be helpful, but high-frequency transducers are more challenging to implement in the combustor due to the higher temperatures.

Tunable Diode Laser Absorption Spectroscopy (TDLAS) sensors can give information on species concentrations and temperature in the combustor. Ref. 6 used TDLAS sensors to measure temperature non-uniformities in a laboratory scramjet combustor. This study found signals that could be used to predict unstart seconds before the event. Ref. 7 used TDLAS sensors and high frequency pressure transducers to track the shock train motion in a laborator scramjet isolator. The TDLAS sensor signals indicated large shock train motions $20-40 \mathrm{~ms}$ before the pressure signals. TDLAS sensors can be used on flight vehicles, but they require pitch and catch optics and can be challenging to integrate. ${ }^{8}$

In the current research program, we investigated the potential of passive optical combustion sensors for scramjet engine control. These sensors collect the light emissions from combustion to detect flame properties and combustor transients. The measurement is passive in that no laser light is projected into the flow. The sensors can have a frequency response in the $\mathrm{MHz}$ range, far above any scramjet combustor transients. Only flush-mounted, fiber-coupled optical components are needed. This minimizes alignment and cooling requirements making the sensors relatively easy to apply to flight vehicles.

\section{High-Frequency Passive Optical Combustion Sensors}

\section{A. Flame Spectroscopy for Measurement of Equivalence Ratio and Heat Release}

Light emissions from combustion are due to chemiluminescence of excited species and radiation from hot particles such as soot. Some excited radicals such as $\mathrm{OH}^{*}, \mathrm{CH}^{*}$, and $\mathrm{C}_{2}{ }^{*}$ have emissions in distinct bands allowing them to be isolated from the broadband radiation. In many flames, the magnitude of the flame luminosity (as a whole or in particular spectral bands) is proportional to the heat release rate, and the ratio of two combustion radicals $\left(\mathrm{OH} * / \mathrm{CH}^{*}, \mathrm{C}_{2} * / \mathrm{OH}^{*}, \mathrm{C}_{2} * / \mathrm{CH}^{*}\right)$ is a function of equivalence ratio. Therefore, it is possible to determine heat release rate and equivalence ratio through measurement of the flame emissions.

$\mathrm{CH}^{*}$ emissions have often been used as a measure of a local heat release rate in hydrocarbon. ${ }^{9-13}$ Care must be taken in interpreting the results because $\mathrm{CH}^{*}$ emissions can be influenced by equivalence ratio and strain rate as well. ${ }^{9,12}$ For the current study, we assumed that $\mathrm{CH}^{*}$ emissions are proportional to the local heat release rate. However, this correlation between $\mathrm{CH}^{*}$ and q does not need to be quantitatively accurate to use the sensor signals for control. 
Flame equivalence ratio has been shown to be correlated with the ratio of emissions from various combustion radicals. For methane or natural gas flames the ratio of $\mathrm{OH}^{*} / \mathrm{CH}^{*}$ is most often used. For larger hydrocarbons, $\mathrm{C}_{2} *$ becomes more prevalent, and combinations of $\mathrm{C}_{2} * / \mathrm{OH}^{*}$ and $\mathrm{C}_{2} * / \mathrm{CH}^{*}$ have been correlated with equivalence ratio. ${ }^{14,10,15}$ We used the $\mathrm{C}_{2} * / \mathrm{CH}^{*}$ ratio to estimate the local flame equivalence ratio for the current study. We chose not to use $\mathrm{OH}^{*}$ due to the lower availability of solid-state photodetectors with ultraviolet sensitivity and the increased pressure sensitivity of $\mathrm{OH}^{*}$ compared with $\mathrm{CH}^{*}{ }^{16,17}$ Ref. 10 found that the ratio of $\mathrm{C}_{2} * / \mathrm{CH}^{*}$ emissions was approximately equal to $\Phi$ in premixed n-heptane flames. We assumed this same relationship between $\mathrm{C}_{2} * / \mathrm{CH}^{*}$ and $\Phi$ for the scramjet combustion in the current study. This is expected to be qualitatively, but not quantitatively accurate. To improve the accuracy of the $\Phi$ measurement in the future, premixed flame calibration experiments are needed with scramjet relevant temperatures, pressures, and fuels.

\section{B. Sensor Hardware}

Figure 1 shows the sensor we used for the current research project. A 9.4-mm diameter lens focused flame emissions from the measurement volume onto fiber-optic bundle. The fiber-optic bundle was mated with spectral filters and photodetectors within the sensor enclosure. These photodetectors measured the light in particular spectral bands. We used photomultiplier tubes (PMTs) for the photodetectors on this laboratory sensor due to their high sensitivity and large dynamic range. The PMT modules in this sensor have a $50 \mathrm{kHz}$ frequency response which is expected to be sufficient to resolve all relevant engine time scales. A National Instruments USB-6356 DAQ card reads the voltage output from each PMT module simultaneously at $100 \mathrm{kHz}$. A LabVIEW ${ }^{\circledR}$ program recorded this data for post-processing.

The sensor we built for this project contains one equivalence ratio $(\Phi)$ and one heat-release-only (q) sensor. The equivalence ratio sensor requires the measurement of four spectral bands: $\mathrm{CH}^{*}$ signal $\left(430 \mathrm{~nm}\right.$ center), $\mathrm{CH}^{*}$ background ( $455 \mathrm{~nm}$ center), $\mathrm{C}_{2}{ }^{*}$ signal $\left(513 \mathrm{~nm}\right.$ center), and $\mathrm{C}_{2} *$ background $(530 \mathrm{~nm}$ center). The background measurements are used to determine the level of broadband background radiation adjacent to the measurement bands. This background radiation is subtracted from the measurement bands before calculating the $\mathrm{C}_{2} * / \mathrm{CH}^{*}$ ratio.

We used a randomized 1 to 4 split fiber bundle to bring $1 / 4$ of the light collected to four PMTs. A spectral filter was placed in a $1 / 2$ " lens tube between the fiber end and PMT. The spectral filters are easily swappable. This allowed us to convert the $\Phi$-q sensor into four q sensors for some tests to measure the heat release rate in multiple locations simultaneously.
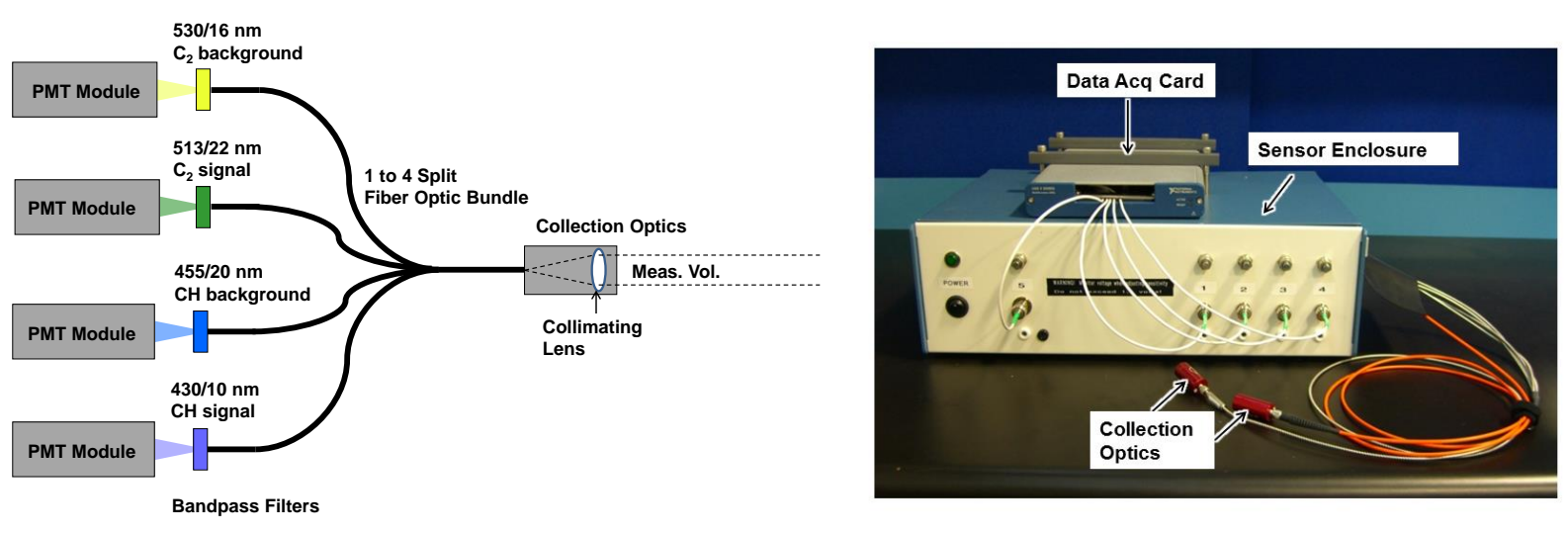

Figure 1. Passive optical sensor schematic (left) and photo (right).

\section{Sensor Data Filtering}

The sensor data was low-pass filtered digitally to reduce high frequency noise. We used moving average low-pass filtering for the data presented in this paper, but other types of low-pass filtering (e.g., Windowed Finite Impulse Response or Butterworth Infinite Impulse Response) give similar results. The low-pass filtering causes a time lag in the filtered data because only past data is used. This time lag is undesirable, but unavoidable for any filter that can be implemented in real time for engine control. The filtered data shown in Section IV include the time lag caused by the low-pass filtering. A 3 ms moving average filter causes a $1.5 \mathrm{~ms}$ time lag in the filtered data. 


\section{Facilities and Test Conditions}

We tested the passive optical sensors in a dual-mode scramjet combustor located at the University of Michigan (UofM). A wide range of test conditions were explored to investigate the ability of the sensor to detect and predict prototypical scramjet combustion transients.

\section{A. Test Setup}

The UofM scramjet combustor is shown in Figure 2. It consists of a Mach 2.2 nozzle and constant area isolator upstream of a combustion region. The primary fuel is injected upstream of a wall cavity and is followed by a diverging wall. The inlet air can be heated to stagnation temperatures between 1,050 and $1,500 \mathrm{~K}$ through a combination of a $250 \mathrm{~kW}$ electric resistance heater and a hydrogen fueled vitiator. Additional oxygen is injected to maintain a $0.21 \mathrm{O}_{2}$ mole fraction in the heated products. Approximately 10 runs each consisting of 4 seconds of main flow combustion can be completed per day in this un-cooled, blow-down facility.

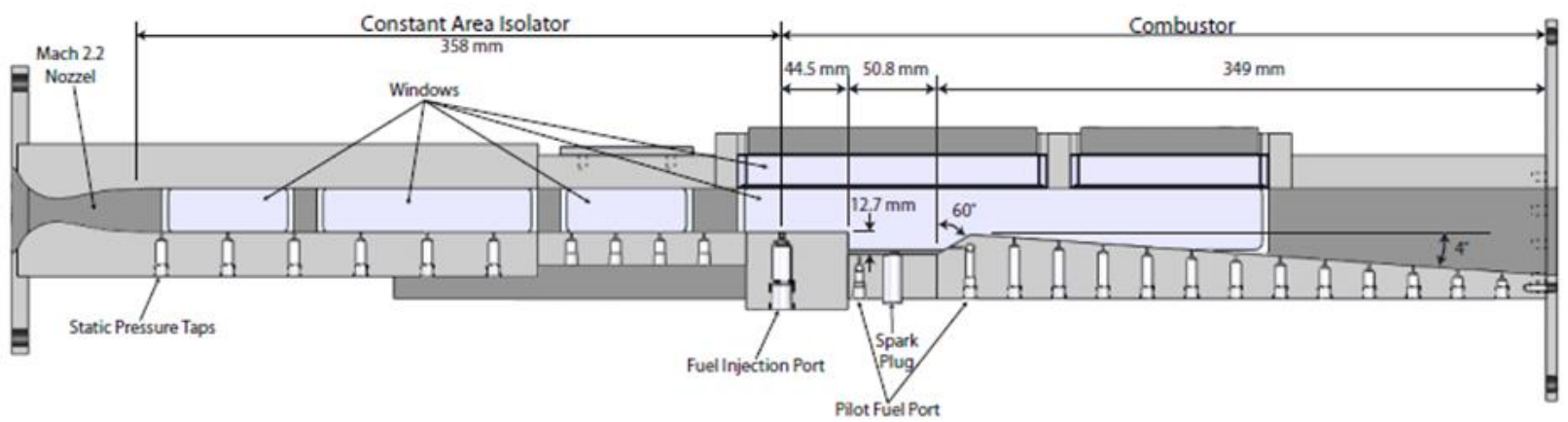

Figure 2. UofM scramjet combustor.

We used the passive optical sensors to view the reaction zone through the existing fused silica windows. The collection optics were held in a mounting plate shown in Figure 3. The different available measurement locations are labeled M1-M14. Our focus was on the measurement locations in the flame stabilization region, M1-M7. Data from the optical sensors was recorded at $100 \mathrm{kHz}$ along with a high-frequency pressure transducer located 6.25 inches upstream of the cavity. The optical measurement locations were switched between runs. A high-speed camera recorded video of the combustion at $1 \mathrm{kHz}$ through the window opposite the passive optical sensor. The camera was synchronized with the optical sensor and high frequency pressure measurements. The combustor data acquisition system recorded flow rates, temperatures, and static pressure at 16 locations in the test section at $40 \mathrm{~Hz}$.
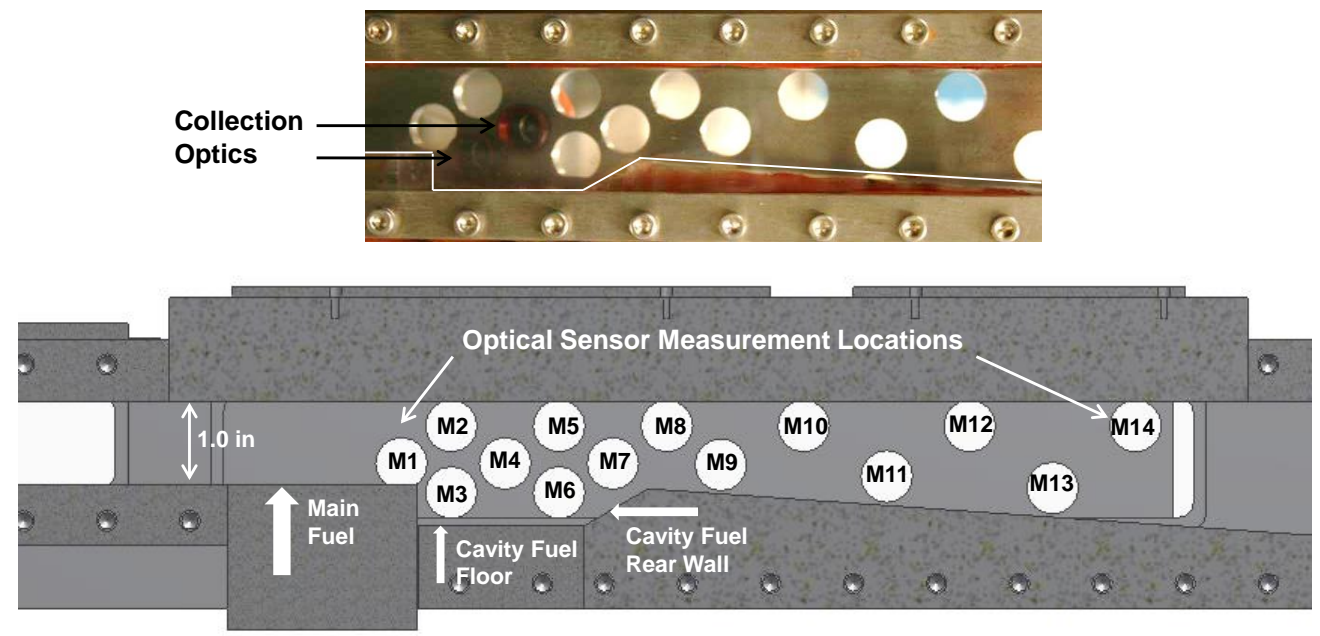

Figure 3. Collection optics mounting and measurement mocations. Optics image the reaction zone through existing fused silica windows. The actual measurement volume is $\mathbf{5 m m}$ diameter circle in the center of the mounting plate holes. 


\section{B. Run Conditions}

Table 1 lists the range of operating conditions and transients we tested in this study. We started using a fuel mixture of $50 \%$ hydrogen $\left(\mathrm{H}_{2}\right)$ and $50 \%$ ethylene $\left(\mathrm{C}_{2} \mathrm{H}_{4}\right)$ by volume. We needed carbon content in the fuel, because we are measuring carbon-based radicals. The addition of hydrogen increases the fuel reactivity and allows for an increased stable operating window in the combustor. After some initial testing, we switched to a fuel mixture of $75 \%$ hydrogen $\left(\mathrm{H}_{2}\right)$ and $25 \%$ ethylene $\left(\mathrm{C}_{2} \mathrm{H}_{4}\right)$ to improve the combustor stability.

The last row of Table 1 lists the combustor operating modes and transients that we examined for each type of fuel. There are two primary combustion stabilization modes in this combustor which are described by Ref. 4. Cavity stabilized combustion, shown in Figure 4, occurs for lower air stagnation temperatures and consists of a premixed flame spreading from the cavity leading edge. Jet-wake stabilized combustion, shown in Figure 5, occurs for higher air stagnation temperatures and consists of a lifted jet flame stabilized upstream of the cavity leading edge. For intermediate air stagnation temperatures the flame oscillates between the two modes: there is not a stable intermediate position. In this study, we investigated both stabilization modes, oscillation between the two modes, and a blow-off re-ignition oscillation. We also enforced transients by cutting off the pilot fuel or changing the main fuel flow rate during runs.

\begin{tabular}{|l|c|c|}
\hline \multicolumn{3}{|c|}{ Table 1. UofM Combustor Operating Conditions } \\
\hline \hline \multicolumn{1}{|c|}{ Operating Parameter } & $\begin{array}{c}\text { Range Tested } \\
50 \% \mathrm{H}_{2}-50 \% \mathrm{C}_{2} \mathrm{H}_{4} \text { Fuel }\end{array}$ & $\begin{array}{c}\text { Range Tested } \\
75 \% \mathrm{H}_{2}-25 \% \mathrm{C}_{2} \mathrm{H}_{4} \text { Fuel }\end{array}$ \\
\hline \hline Air Stagnation Temperature $\left(\mathrm{T}_{0}\right)$ & $1,260-1,450 \mathrm{~K}$ & $1,140-1,460 \mathrm{~K}$ \\
\hline Air Stagnation Pressure $\left(\mathrm{P}_{0}\right)$ & $430-600 \mathrm{kPa}$ & $430-600 \mathrm{kPa}$ \\
\hline Overall Equivalence Ratio $\left(\Phi_{\text {global }}\right)$ & $0.40-0.67$ & $0.24-0.49$ \\
\hline Cavity Fuel Fraction $\%$ of total fuel) & $3 \%-5 \%$ & $0 \%-10 \%$ \\
\hline Cavity Fuel Location & Rear Wall & Floor \\
\hline Total Number of Runs (with main flow ignition) & 24 & 72 \\
\hline Combustion Modes and Transients Studied & $\begin{array}{c}\text { Steady Jet-Wake Comb. } \\
\text { Blowout, Re-lgnition Osc. }\end{array}$ & $\begin{array}{c}\text { Steady Jet-Wake Comb. } \\
\text { Steady Cavity Comb. } \\
\text { Main Fuel Ramp-Up/Down } \\
\text { Pilot Fuel Cut-off } \\
\text { Stabilization Mode Osc. }\end{array}$ \\
\hline
\end{tabular}

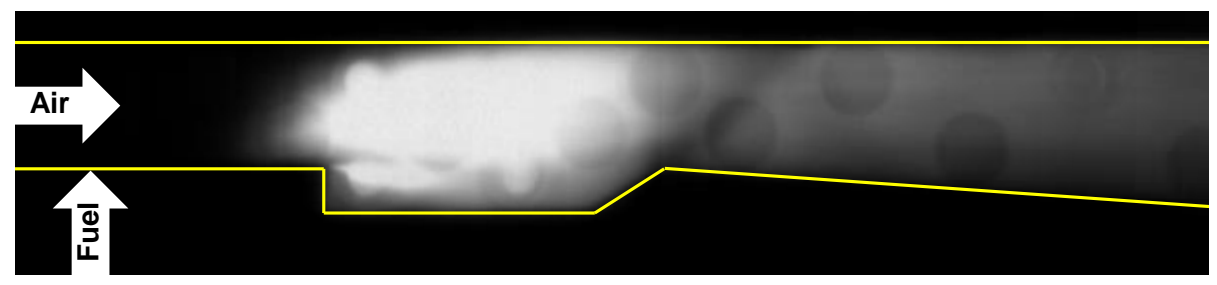

Figure 4. Image of the scramjet flame in the cavity stabilized combustion mode. This type of flame occurs for low air stagnation temperatures (T0<1,200 K for $75 \% \mathrm{H}_{2}-25 \% \mathrm{C}_{2} \mathrm{H}_{4}$ fuel).

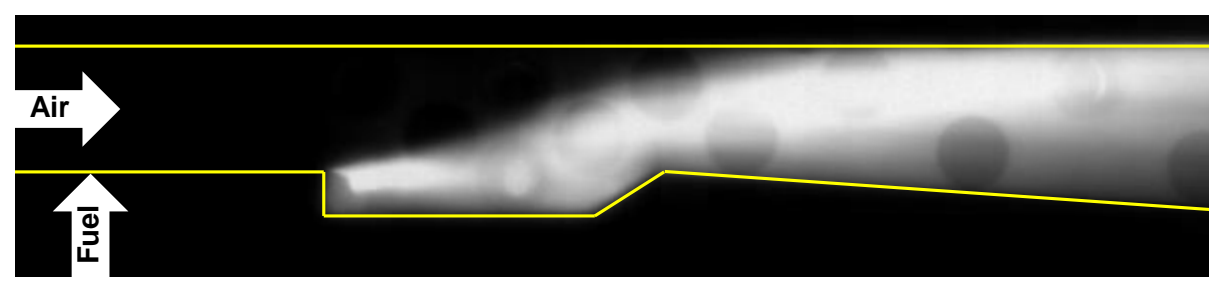

Figure 5. Image of the scramjet flame in the jet-wake stabilized combustion mode. This type of flame occurs for high air stagnation temperatures (T0>1,400 K for $75 \% \mathrm{H}_{2}-25 \% \mathrm{C}_{2} \mathrm{H}_{4}$ fuel). 


\section{Results and Discussion}

\section{A. Measure $\Phi$ in Key Flame Stabilization Locations}

One of the primary ways the $\Phi / q$ sensor could be used by a closed-loop engine controller is to provide an equivalence ratio measurement in a key flame stabilization location. The controller would use this measurement to adjust the fueling to maintain the equivalence ratio and heat release in the optimal range. The data shown in Figure 6 illustrates how this could be done. This figure contains data from a cavity stabilized flame for which the pilot fuel is turned off during the run. The $\Phi / \mathrm{q}$ combustion sensor is located at $\mathrm{M} 3$, which is at the flame base for this combustion mode. With the pilot fuel on (from the cavity floor), there is strong heat release at the flame base, and the flame is quite stable as observed by the combustion sensor and the high-speed movies. The equivalence ratio (from $\mathrm{C}_{2} / \mathrm{CH}^{*}$ ) in the flame base averages $\sim 0.87$ and is relatively stable. After the pilot fuel is turned off, the average flame base equivalence ratio drops to $\sim 0.60$, and the heat release rate drops by a factor of 10 . The flame becomes much more unstable and appears to be on the verge of blowing out.

The sensor shows that the flame is lean and weak in the flame base region with the pilot off, indicating the need for more pilot fuel. This type of information could be used to maintain an optimal pilot fuel flow rate over a range of flight conditions by maintaining $\Phi$ and q within a certain range at this location. In our initial tests, we measured low equivalence ratios at M3 using cavity rear wall fueling. Based on the optical sensor measurement at M3, we switched to cavity floor fueling for the later tests. With the ramped rear wall used in this study, it appears that not enough fuel from the rear wall was making it to the front of the cavity.
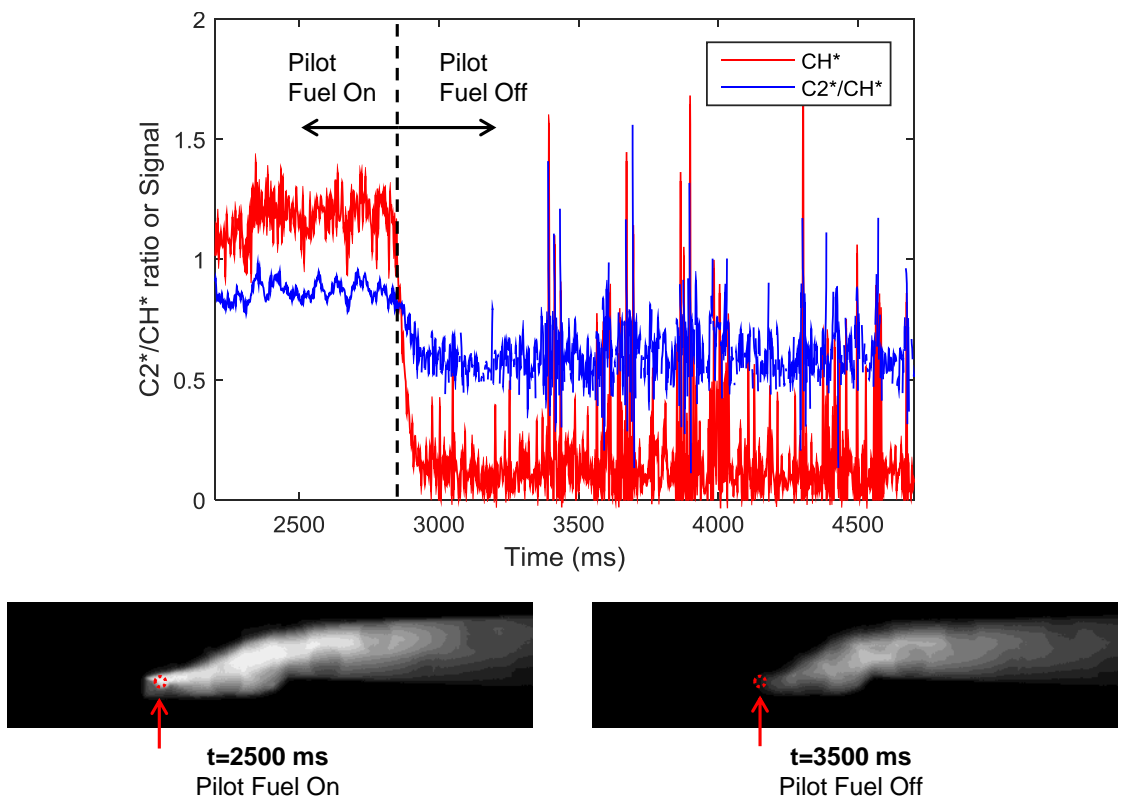

Figure 6. Sensor data at M3 for cavity stabilized flame with the pilot fuel on and off. After pilot fuel is turned off, the average equivalence ratio and heat release rate at M3 drops and the flame becomes much less stable. The sensor data is low-pass filtered with a 3 ms moving average window. The sensor location is marked by the red circle.

\section{B. Flashback Prediction}

In addition to quickly sensing engine transients, the optical sensor may also be used to predict impending transients in some instances. This would potentially allow an engine controller to take preventative action to avoid an un-desirable condition before it occurred. In this project, we were able to use data from the optical combustion sensors to predict flashback events from jet-wake stabilized combustion up to $20 \mathrm{~ms}$ before they occurred. The sensors were able to detect the small downstream movement of the flame that occurs a few ms before the fast flashback events. This is unlikely to be detected reliably through other types of sensors such as pressure transducers, because it would produce a very minor pressure change which could be mimicked by many other slight combustor changes (such as a minor reduction in fuel flow rate). 
We found that flashback from the jet-wake combustion mode was always preceded by a rise in equivalence ratio at M7. This rise was always detected 5 to $20 \mathrm{~ms}$ before flashback actually occurred, but occasionally the rise occurred without a flashback event. Figure 7 shows optical sensor data at M7 for a run with primarily jet-wake stabilized combustion that had four flashback events. Flashback events are indicated by spikes in the heat release rate at M7. The measured equivalence ratio is usually around 0.8 , but rises above 0.95 before every flashback event. This occurs because the rich, premixed flame base moves into the M7 measurement region when the flame shifts downstream. Figure 8 shows a detail of one flashback event along with the corresponding high-speed movie frames.
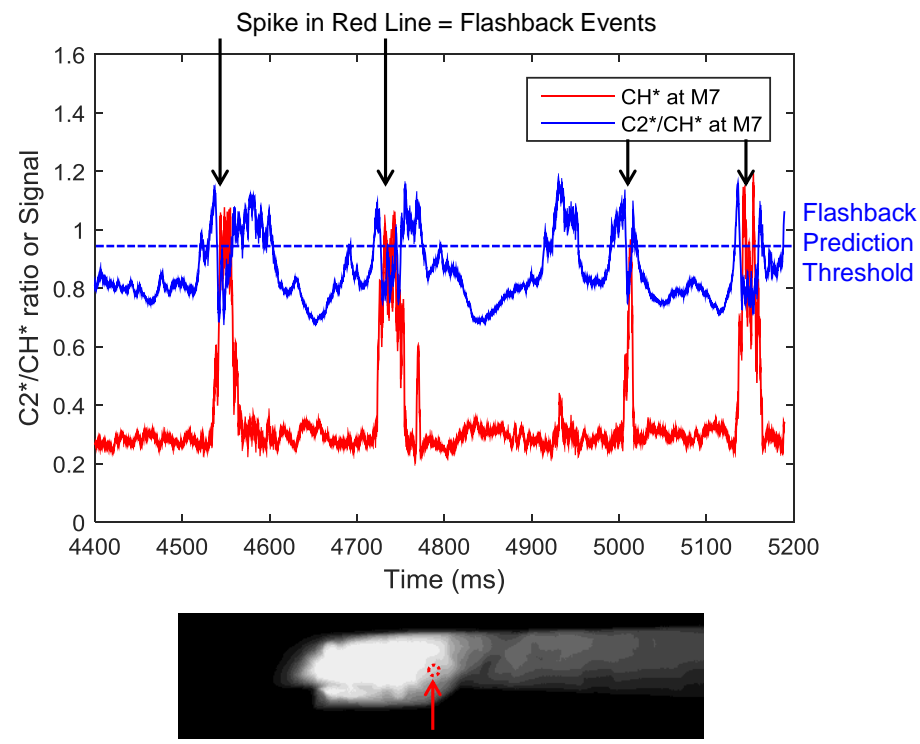

Figure 7. Sensor signal for jet-wake stabilized combustion with flashback events. All four flashback event are preceded by a rise in equivalence ratio (blue line) at M7. The sensor data is low-pass filtered with a 3 ms moving average window. The sensor location is marked by the red circle.
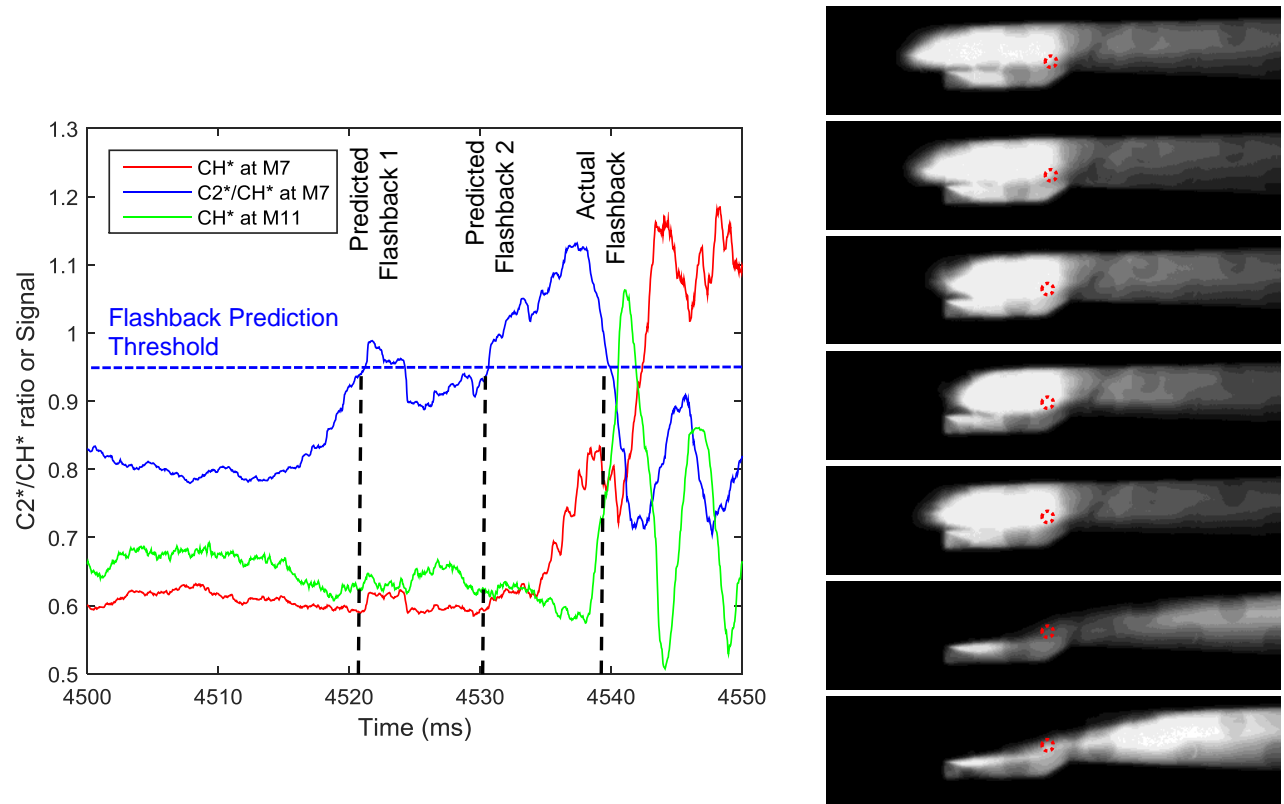

$\mathrm{t}=4500 \mathrm{~ms}$ Jet-Wake Mode

$t=4520 \mathrm{~ms}$

$\mathrm{t}=4530 \mathrm{~ms}$

$\mathrm{t}=4535 \mathrm{~ms}$

$t=4538 \mathrm{~ms}$

$\mathrm{t}=4539 \mathrm{~ms}$

Flashback

$\mathrm{t}=4541 \mathrm{~ms}$ Cavity Mode

Figure 8. Detail of flashback prediction from $\Phi$ sensor. The flashback prediction threshold is $\mathrm{C}_{2} * / \mathrm{CH}^{*}>0.95$ (blue line) at M7. CH*>0.9 at M11 (green line) corresponds to flashback in the high-speed movies. Flashback is predicted $18 \mathrm{~ms}$ before it occurs. The sensor data is low-pass filtered with a 3 ms moving average window. 


\section{Tracking Fluctuations}

The high frequency response of the optical sensor excels in the very dynamic environment of the blow-off re-ignition instability. In this mode, the combustor has periodic main flame blowout and re-ignition events at $\sim 200 \mathrm{~Hz}$. We were able to clearly detect these fast blowout re-ignition events with the optical sensor. We were also able to track the movement of heat release deviations in the combustor through two (or more) heat release sensors at different locations. Figure 9 shows a detail of simultaneous signals from heat release sensors at M3 and M9 for the combustor operating in this mode. Also shown are example flame images at select times. These signals show that the peak in heat release from re-ignition occurs first at the downstream sensor location M9 before moving upstream to M3. The separation in these heat release peaks is only $0.8 \mathrm{~ms}$, so the movement cannot be clearly identified from the $1,000 \mathrm{~Hz}$ high-speed movies. Additional heat release sensors throughout the combustor would help characterize this instability more clearly. Figure 9 also shows the output of the high-frequency pressure transducer located in the isolator. The pressure transducer does not clearly pick up on these very fast blowout re-ignition events because the combustor pressure field does not respond instantaneously. In a closed-loop engine controller, tracking spikes in the heat release throughout the combustor could be useful for predicting unsteady unstart events well before the resulting pressure propagates to the front of the isolator.

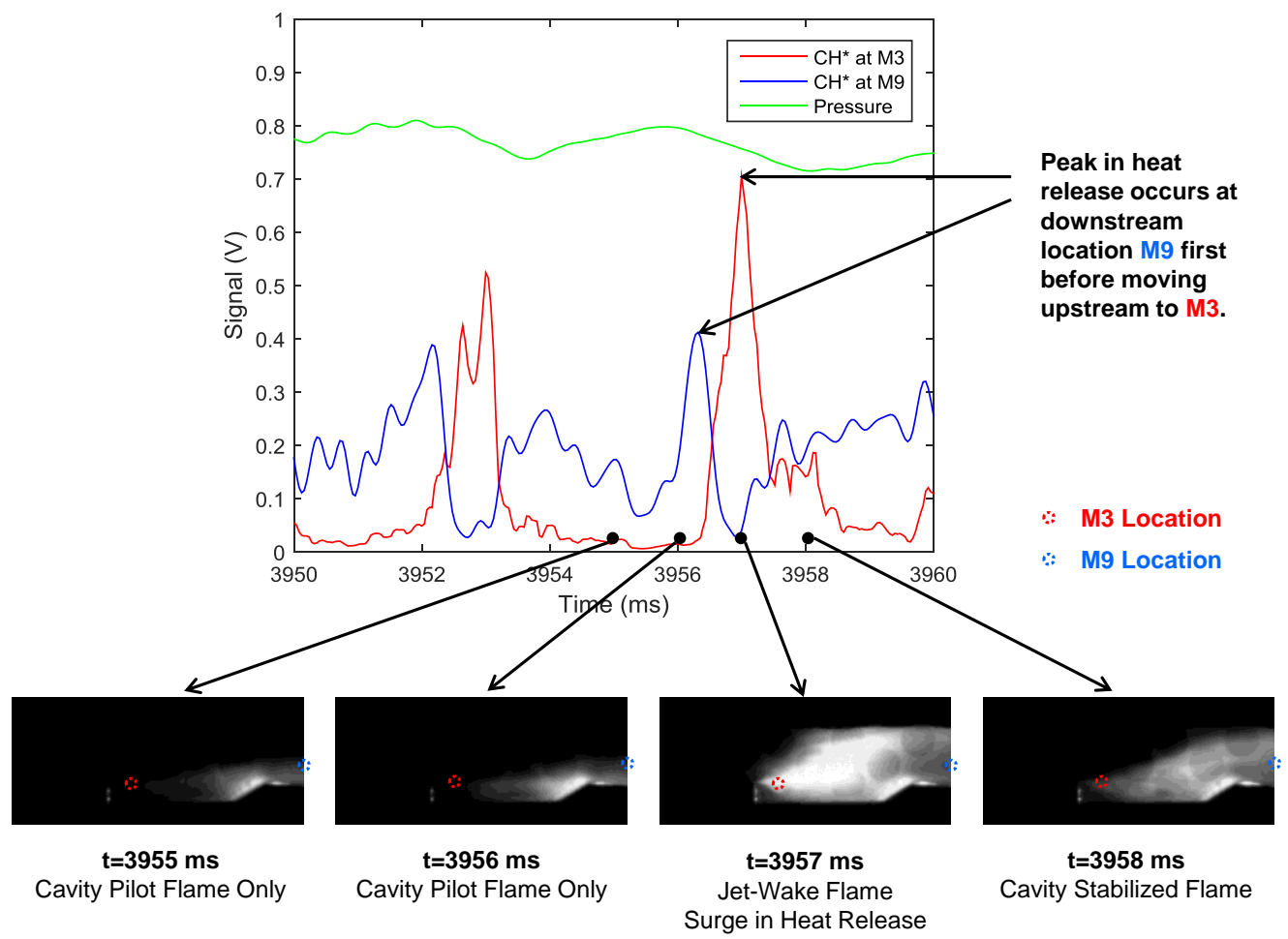

Figure 9. Simultaneous $\mathrm{CH}^{*}$ sensor signals at $\mathrm{M3}$ and $\mathrm{M9}$ for a re-ignition event. Example flame images from select times also shown. Sensor signals show that the increase in combustion starts downstream of the cavity and moves upstream. The sensor signal was $5 \mathrm{kHz}$ low-pass filtered. The sensor locations are marked by red and blue circles.

\section{Instability Modes}

The frequency content of the heat release $\left(\mathrm{CH}^{*}\right)$ signals gives some insight into the dominant combustor modes and locations where they are important. The Fast Fourier Transform (FFT) of the heat release signal varied based on the sensor location and the combustion mode. We found two dominant combustor frequencies: one at $200 \mathrm{Ho} 250 \mathrm{~Hz}$ and one at $\sim 1,000 \mathrm{~Hz}$. The $1,000 \mathrm{~Hz}$ instability is associated with the jet-wake combustion stabilization region. Figure 10 shows an FFT of the heat release throughout the combustor for jet-wake stabilized combustion. The peak instability occurs at $\sim 1,000 \mathrm{~Hz}$ for the upstream measurement locations (M1 and M4). For downstream locations, there is no peak instability. The $200 \mathrm{~Hz}$ instability dominates the other combustion modes, particularly the blow-off re-ignition instability and the case of oscillation between the jet-wake and cavity stabilized modes. Figure 11 shows an FFT of the heat release throughout the combustor for cavity stabilized combustion. There is a peak at $\sim 250 \mathrm{~Hz}$ at 
all locations with signal. This same frequency peak is observed for the case of oscillation between combustion modes and the blow-off re-ignition instability. Interesting, the actual oscillation between the jet-wake and cavity occurs much less frequently than 200 times per second ( 10 times per second on average).
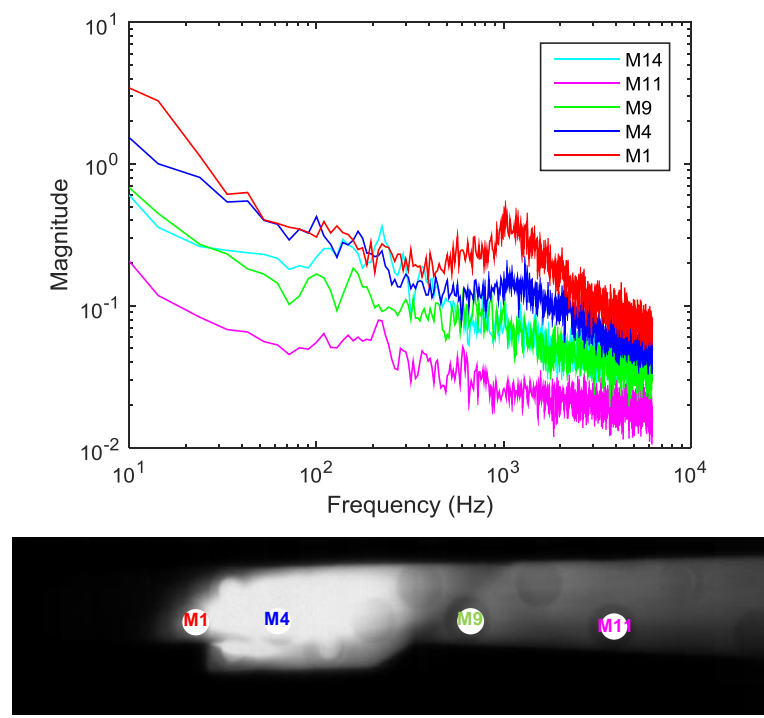

M14

Figure 10. FFT of heat release throughout combustor for the jet-wake stabilized combustion. The dominant frequency is $1,000 \mathrm{~Hz}$ at the upstream locations (M1 and M4). There is not a clear peak instability frequency at the downstream locations.
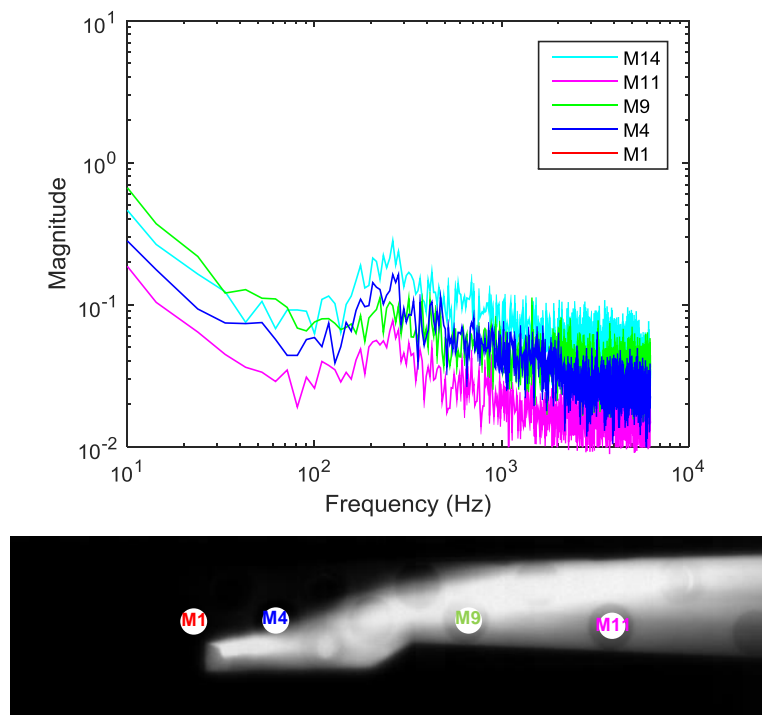

M14

Figure 11. FFT of heat release throughout combustor for the cavity combustion mode. The dominant frequency is $200-250 \mathrm{~Hz}$ at all locations measured.

\section{E. Combustor Time Response}

The sensor can be used to study characteristic times in the combustor due to its very fast $(50 \mathrm{kHz})$ response. Cases where the combustion stabilization mode oscillates are interesting, because they contain several transients. The stabilization mode transition is generally rapid; occurring over approximately one millisecond. In between transitions, the combustion mode stays constant for anywhere from a few milliseconds to tens or hundreds of milliseconds. Figure 12 contains sensor data at M4 and M3 for a case of oscillating combustion modes. At M4, the equivalence ratio changes in a few milliseconds when the mode transition changes. This change in equivalence ratio is most likely dominated by a change in the flame location and character (premixed vs. mixing limited) during this mode transition. However, the mode transition likely has some effect on the fuel distribution as well. At M3 (in the 
cavity) the response is much different. While the mode transitions still occur in just a few milliseconds, the changes in equivalence ratio, and to a lesser extent heat release, occur much more slowly (over tens of milliseconds). The likely reason for the slower change at M3 is the limited transport rate between the cavity and the main flow. The average flow residence time in the cavity is likely much longer than in the main flow, so conditions change more slowly.
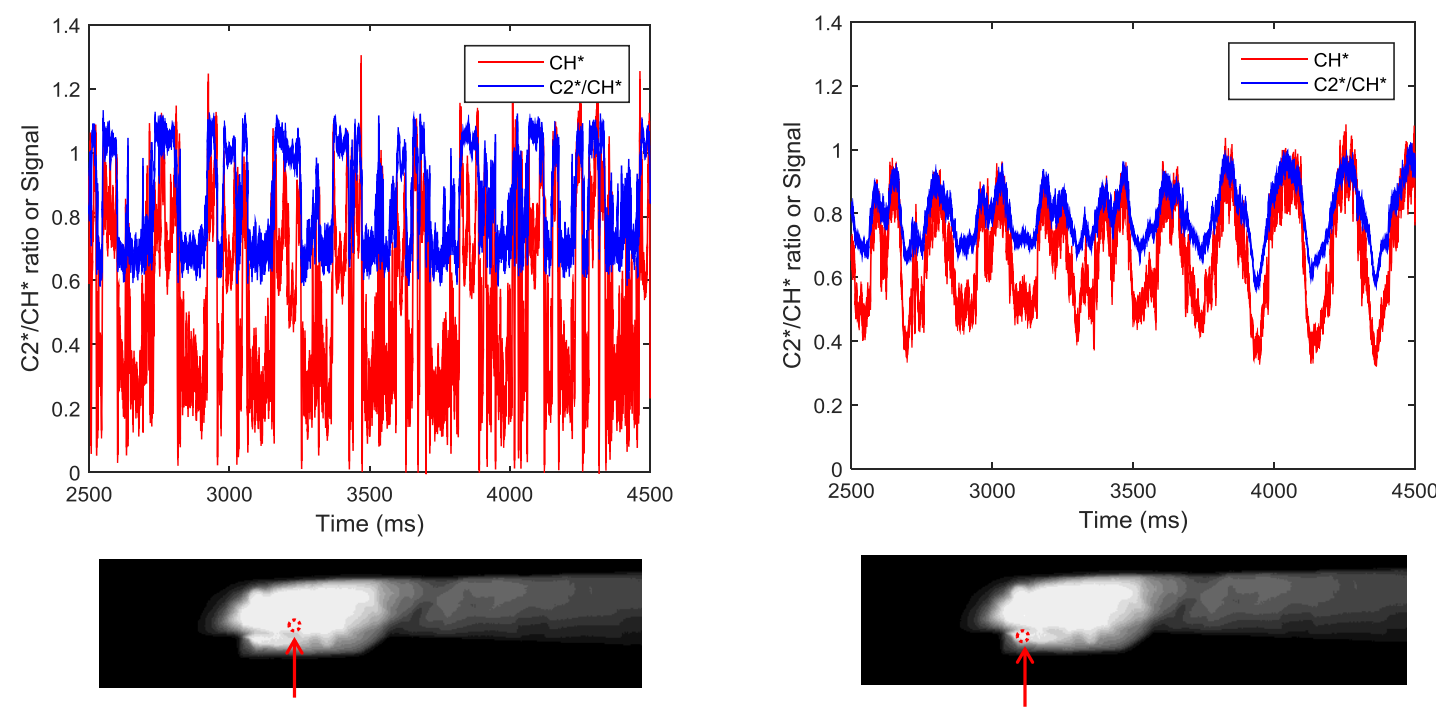

Figure 12. Sensor signals at M4 (top) and M3 (bottom) for cases with oscillating combustion stabilization modes. At M4, the equivalence ratio and heat release responds virtually instantaneous to changes in the stabilization mode ( $1 \mathrm{~ms})$. At M3, changes in equivalence ratio and heat release occur much more slowly after a stabilization mode changes (>10 ms).

\section{F. Sensor Signal-to-Noise Ratio (SNR)}

Two sources of noise for the optical sensors are shot noise and background emission noise. Shot noise occurs due to the discrete and statistical nature of photons and is only significant at very low-light levels and/or fast measurements. The SNR due to shot noise is:

$$
S N R=\sqrt{\eta N}
$$

where $\eta$ is the detector quantum efficiency and $N$ is the number of photons impacting in the time period of interest. For the light levels measured in the UofM experiments, we calculated the shot noise SNR to be greater than 200 for a $10 \mathrm{kHz}$ measurement. The light levels in more realistic scramjets will be higher due to the higher heat release rate. Therefore, shot noise is not expected to be a significant source of error for these passive sensors.

Background noise occurs because the sensor measures broadband background radiation in addition to the chemiluminescence peaks. This broadband background radiation increases with pressure. Our sensor measures background bands directly adjacent to the signal bands to account for this background radiation. However, this correction is not perfect due to the variation in the background intensity with wavelength. Therefore, the background noise in the corrected signal will increase as the background emission level increases. We acquired data with the sensor for combustor static pressures between $65 \mathrm{kPa}$ (pilot only, scramjet mode combustion) and $250 \mathrm{kPa}$ (ramjet mode combustion in cavity region). Table 2 shows the ratio of the signal strength (per $\mathrm{nm}$ filter bandwidth) in the signal bands vs. the backgrounds bands at these two extreme pressures for the $75 \% \mathrm{H}_{2}, 25 \% \mathrm{C}_{2} \mathrm{H}_{4}$ fuel blend. This table shows that the sensor signal remains relatively strong over the range of pressures tested. The noise resulting from imperfect background correction is likely significantly less than the measured background signal. 


\begin{tabular}{|c|c|c|}
\hline \multicolumn{3}{|c|}{ Table 2. Sensor Signal-to-Background Ratio for Different Pressures $\left(75 \% \mathrm{H}_{2}, 25 \% \mathrm{C}_{2} \mathrm{H}_{4}\right.$ fuel $)$} \\
\hline \hline $\begin{array}{c}\text { Combustor Static Pressure } \\
(\mathrm{kPa})\end{array}$ & $\begin{array}{c}\mathrm{C}_{2}{ }^{*} \text { signal per } \mathrm{nm} / \mathrm{C}_{2}{ }^{*} \\
\text { background per } \mathrm{nm}\end{array}$ & $\begin{array}{c}\mathrm{CH}^{*} \text { signal per } \mathrm{nm} / \mathrm{CH}^{*} \\
\text { background per } \mathrm{nm}\end{array}$ \\
\hline \hline $65 \mathrm{kPa}$ & $\sim 7$ & $\sim 7$ \\
\hline $250 \mathrm{kPa}$ & $\sim 3$ & $\sim 5$ \\
\hline
\end{tabular}

\section{Summary and Conclusions}

In this study, we investigated the potential of passive optical combustion sensors to be used for scramjet engine control and research. We built a fiber-coupled sensor to measure $\mathrm{C}_{2} *$ and $\mathrm{CH}^{*}$ emissions at high frequency and used the data to estimate the local heat release rate $(q)$ and flame equivalence ratio $(\Phi)$. We tested the sensor in a laboratory dual-mode scramjet combustor for a range of conditions and transients. Some of the key results and conclusions from these tests are listed below:

- The $\Phi$-q sensor can be used to measure the equivalence ratio and heat release rate in key flame stabilization regions. This measurement could be used by a closed-loop controller to maintain optimal flame stability.

- The high-frequency sensors respond very quickly to engine transients, allowing them to track heat release perturbations throughout the combustor that could lead to isolator unstart.

- Using the optical combustion sensor data, we developed a method to predict flashback from the jet-wake combustion mode before it occurred (5 to $20 \mathrm{~ms}$ warning). This type of information could potentially be used by a closed-loop controller to take preventative action to avoid this flashback.

- The sensor data can be used to determine the primary combustion instability frequencies and regions where they are dominant.

- The signal to background light level of the sensor decreases as the pressure increases. This ratio was still relatively high (3-5) at $250 \mathrm{kPa}$ for the hydrogen-ethylene fuel mixture.

\section{Acknowledgments}

This work was supported by a Phase I SBIR award from the Air Force. The support of Dr. Jeffery Donbar and the AFRL is greatly appreciated.

\section{References}

${ }^{1}$ Valdivia, A., Yuceil, K.B., Wagner, J.L., Clemens, N.T., Dolling, D.S., “Active Control fo Supersonic Inlet Unstart Using Vortex Generator Jets," AIAA Paper 2009-4022, June 2009.

${ }^{2}$ Srikant, S., Wagner, J.L., Valdivia, A., Akella, M.R., and Clemens, N.T., "Unstart Detection in a Simplified-Geometry Hypersonic Inlet-Isolator Flow," Journal of Propulsion and Power, Vol. 26, No. 5, 2010.

${ }^{3}$ Hutzel, J.R., Decker, D.D., Cobb, R.G., King, P.I., Veth, M.J., and Donbar, J.M., "Scramjet Isolator Shock Train Location Techniques," AIAA Paper 2011-402, January 2011.

${ }^{4}$ Micka, D.J. and Driscoll, J.F., "Combustion Characteristics of a Dual-Mode Scramjet Combustor with Cavity Flameholder," Proceedings of the Combustion Institute, Vol. 32, 2009, pp. 2397-2404.

${ }^{5}$ Fotia, M.L. and Driscoll, J.F., "Ram-Scram Transition and Flame/Shock-Train Interactions In a Model Scramjet Experiment," Journal of Propulsion and Power, Vol. 29, 2012, pp. 261-273.

${ }^{6}$ Rieker, G.B., Jeffries, J.B., Hanson, R.K., Mathur, T., Gruber, M.R., Carter, C.D., "Diode Laser-Based Detection of Combustion Instabilities with Application to a Scramjet Engine," Proceedings of the Combustion Institute, Vol. 32, 2009, pp. 831-838.

${ }^{7}$ Donbar, J.M., Brown, M.S., Linn, G.J., "Simultaneous High-Frequency Pressure and TDLAS Measurements in a SmallScale Axisymmetric Isolator with Bleed," 50 $0^{\text {th }}$ AIAA Aerospace Sciences Meeting, Nashville, Tennessee, January 2012, AIAA Paper 2012-0331.

${ }^{8}$ Sappey, A.D, et al., "Flight-Ready TDLAS Combustion Sensor for the HIFiRE 2 Hypersonic Research Program," Zolo Technologies, 2009, AEDC-TR-10-T-6.

${ }^{9}$ Najm, H.N. Paul, PH., Mueller, C.J. and Wyckoff, P.S., "On the Adequacy of Certain Experimental Observables as measurements of Flame Burning Rate," Combustion and Flame, Vol. 113, 1998, pp. 312-332.

${ }^{10}$ Morrell, M.R., Seitzman, J., Wilensky, M., Lee, J., Lubarsky, E., and Zinn, B.T., "Interpretation of Optical Flame Emissions for Sensors in Liquid-Fueled Combustion," 39th AIAA Aerospace Sciences Meeting and Exhibit, Reno, Nevada, January 2001, AIAA Paper 2001-0787.

${ }^{11}$ Higgins, B., McQuay, M.Q., Lacas, F., Candel, S., "An Experimental Study on the Effect of Pressure and Strain Rate on CH Chemiluminescence of Premixed Fuel-Lean Methane/Air Flames,” Fuel, Vol. 80, 2001, pp. 1583-1591. 
${ }^{12}$ Hardalupas, Y., Orain, M., "Local Measurements of the Time-Dependent Heat Release Rate and Equivalence Ratio Using Chemiluminescent Emission from a Flame," Combustion and Flame, Vol. 139, 2004, pp. 188-207.

${ }^{13}$ Micka, D.J., Torrez, S.M. and Driscoll, J.F., "Heat Release Distribution in a Dual-Mode Scramjet CombustorMeasurements and Modeling," 16th AIAA/DLR/DGLR International Space Planes and Hypersonic Systems and Technologies Conference, Bremen, Germany, 19-22 October, 2009.

${ }^{14}$ Clark, T.P., "Studies of $\mathrm{OH}, \mathrm{CO}, \mathrm{CH}$, and $\mathrm{C}_{2}$ Radiation from Laminar and Turbulent Propane-Air and Ethylene-Air Flames," NACA TN 4266, 1958.

${ }^{15}$ Muruganandam, T.M., Kim, B., Olsen, R., Patel, M., Romig, B., Seitzman, J.M., "Chemiluminescence Based Sensors for Turbine Engines," $39^{\text {th }}$ AIAA Joing Propulsion Conference, Huntsville, AL, July 20-23, 2003.

${ }^{16}$ Nori, V.N., Seitzman, J.M., "CH* Chemiluminescence Modeling for Combustion Diagnostics," Proceedings of the Combustion Institute, Vol. 32, 2009, pp. 895-903.

${ }^{17}$ Ballester, J., Garcia-Armingol, T., "Diagnostic Techniques for the Monitoring and Control of Practical Flames," Progress in Energy and Combustion Science, Vol. 36, 2010, pp. 375-411. 